\title{
PULMONARY INFLAMMATORY RESPONSE MODULATION BY ESMOLOL IN A ONE-LUNG VENTILATION EXPERIMENTAL MODEL DURING LUNG RESECTION SURGERY
}

\author{
Ramos-Cerro S. ${ }^{1}$, Garutti I. 1, Chamorro E. 1, Rancan L. 2, Vara E. ${ }^{2}$, Simon C. ${ }^{1}$
}

${ }^{1}$ Hospital General Universitario Gregorio Marañón, Madrid, Spain. ${ }^{2}$ Universidad Complutense de Madrid, Biochemistry. Madrid, Spain.

\section{BACKGROUND AND GOAL OF STUDY}

One-lung ventilation (OLV) is usually needed in lung resection surgery (LRS) and is associated with lung inflammatory response (LIR). Esmolol (E) modulates this response in different clinical settings. The aim of this study was to determine the role of $E$ on the LIR induced by LRS with OLV.

\section{MATERIAL AND METHODS}

21 mini-pigs were randomly assigned to 3 different groups: CONTROL (C), ESMOLOL (E), or SHAM (S). E group received and intravenous esmolol bolus $(0.5 \mathrm{mg} / \mathrm{kg})$ after induction, and then a continuous perfusion of $0.05 \mathrm{mg} / \mathrm{kg} / \mathrm{min}$ during the whole procedure. S group underwent a left thoracotomy without being exposed to LRS or OLV. At the end of LRS the animals were awakened and after 24 hours they lung biopsies were obtained under general anesthesia. Bronchoalveolar lavages and lung biopsies were analysed to measure diferente biomarkers of inflammation and glycocalix damage. Data is expressed as mean \pm standard deviation. ANOVA test was used to determine differences between 3 groups. MannWhitney test was used to compare $C$ vs $E$ groups. Values of $p<0,05$ were considered significant.

\section{$\underline{\text { RESULTS }}$}

BRONCHOALVEOLAR LAVAGE

600

400

200

0

Baseline OLV 120' TLV 60' 24 h

NO

30

20

10

0

Baseline OLV 120' TLV 60' $24 \mathrm{~h}$

300

200

100

0 IL-1

nControl $₫$ Esmolol $=$ SHAM

$p$ represents $\mathrm{E}$ vs $\mathrm{C}$ All units are arbitrary

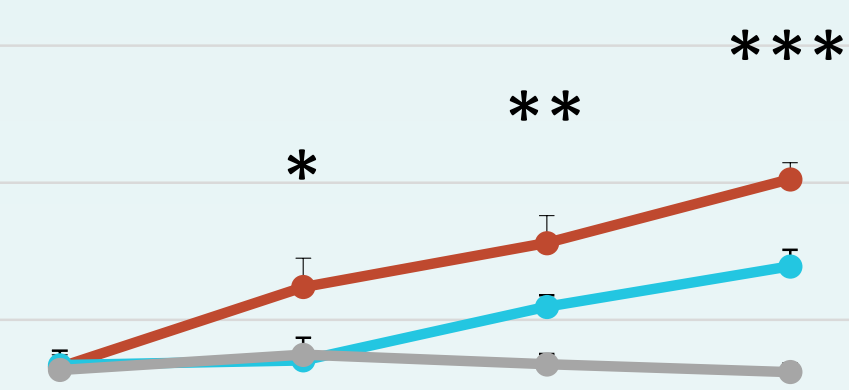

$* \mathrm{P}<0,001$

$* * p<0,001$

$* * * \mathrm{p}<0,001$

$* p=0,009$

$* * p=0,009$

0

100
OLV: one lung ventilation TLV: two lung ventilation

\section{LUNG BIOPSY}

ICAM

50
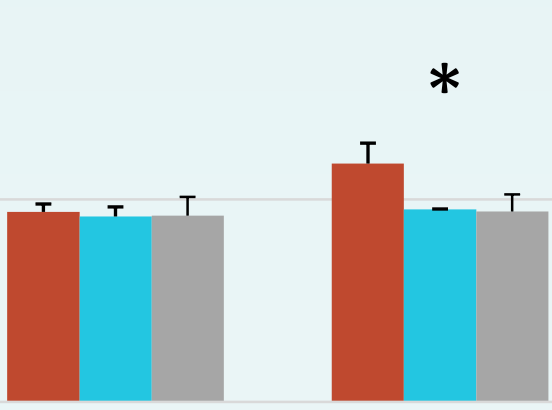

ML 24h

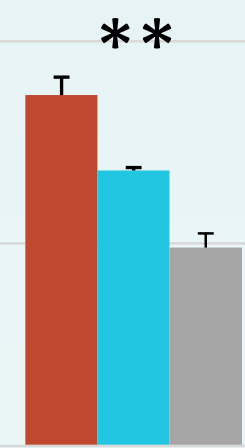

LUL 24h

TNF alfa

$* p=0,0090,4$

$* * p=0,009$

0

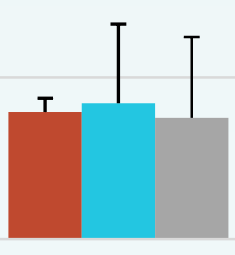

Baseline
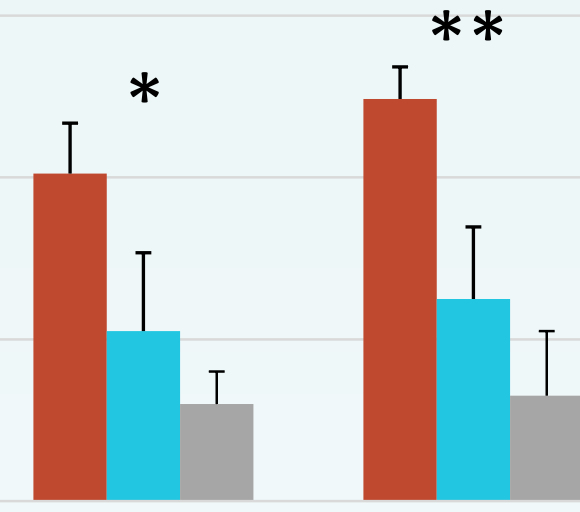

$M L 24 h$

LUL 24h

LUNG EDEMA

$* p=0,006$

$* * p=0,006$
$* p=0,001$

$* * p<0,05$

0

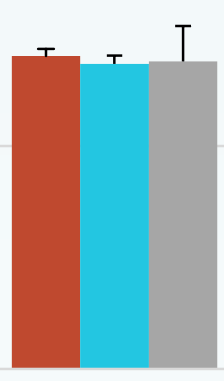

Baseline

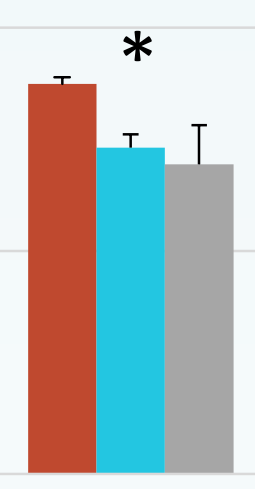

ML 24h

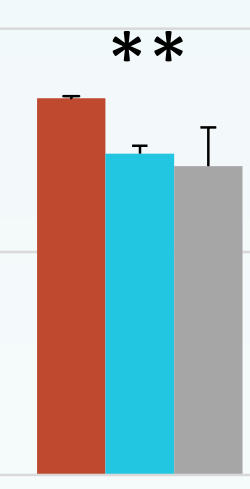

LUL 24h

\section{CONCLUSIONS}

Intraoperative esmolol continuous perfusion during lung resection surgery atenuates the inflammatory response intraoperatovely and $24 \mathrm{~h}$ post surgery.

These antiinflamatory effects may be related to the blockage of the cathecolaminergic receptors expressed by inflamatory response cells in the airway. 